\title{
EVALUATION OF FIRST ORDER ERROR INDUCED BY CONSERVATIVE-TRACER TEMPERATURE APPROXIMATION FOR MIXING IN KARSTIC FLOW
}

\author{
Philippe Machetel \\ Géosciences Montpellier UMR5243 CNRS/UM2, Place Eugène Bataillon-CC60, 34095 Montpellier cedex5, France, \\ philippe.machetel@laposte.net
}

\section{David A. Yuen}

Minnesota Supercomputing Institute and Department of Earth Science, University of Minnesota, 310 Pillsbury Dr. SE, Minneapolis, MN 55455, USA, and School of Environmental Studies, China

University of Geosciences, Wuhan, China,daveyuen@gmail.com

\section{Abstract}

Fluid dynamics in karst systems is complex due to the heterogeneity of hydraulic networks that combine the Porous Fractured Matrix (PFM) and the interconnected drains (CS). The complex dynamics often requires to be treated as "black boxes" in which only input and output properties are known. In this work, we propose to assess the first-order error induced by considering the temperature as a conservative tracer for flows mixing in karst (fluvio-karsts). The fluvio-karstic system is treated as an open thermodynamic system (OTS), which exchanges water and heat with its surrounding. We propose to use a cylindrical PFM drained by a water saturated cylindrical CS, connected on one side to a sinkholes zone and, to the other, to a resurgence flowing at the base level of the karstic system. The overall structure of the model is based on the conceptual model of fluviokarst developed by White $(2002,2003)$. This framework allows us to develop the equations of energy and mass conservation for the different parts of the OTS. Two numerical models have been written to solve these equations: 1) the so-called AW (for Adiabatic Wall) configuration that assumes a conservative tracer behavior for temperature with no conductive heat transfer, neither in the liquid, nor in the PFM or even through the wall separating the CS from the PFM; and, 2), the CW (for Conductive Wall) configuration that takes into account the heat and mass transfers in water and from water to aquifer rocks both in the CS and in the PFM. Looking at the large variability of karstic system morphologic properties, dimensionless forms of the equations have been written for both $\mathrm{AW}$ and $\mathrm{CW}$ configurations. This approach allows us to gather the physical, hydrological and morphological properties of karstic systems into four dimensionless Peclet, Reynold, Prandtl and dimensionless diffusivity numbers. This formalism has been used to conduct a several orders of magnitude parametric exploration based on the Peclet and the Reynolds numbers. The final errors, between the AW and CW configurations, remain less than $1 \%$ over all of the parametric range. The combination of error curves bounds a closed volume in error space that gives a first upper bound of the error made by considering the temperature as a conservative tracer. Applying the method to an illustrative example of karst allows us to reach a first order error within a few degrees ${ }^{\circ} \mathrm{C}$.

\section{Introduction}

Karst aquifers are often considered as potential solutions for meeting water needs required by agriculture, industry and human consumption. A highlight is the ability of these systems to return, during the dry season, the rainfalls of the watershed. However, exploitation by surface, or underground catchment, or pumping of these resources requires cautions to not jeopardize the balance of downstream ecological systems (Weber et al, 2006; Jemcov, 2007). However, exploitation of such resources by surface catchment, underground catchment or pumping requires careful evaluation in order not to jeopardize the balance of ecological systems downstream (Weber et al., 2006; Jemcov, 2007).

Karst environments present broad spectra of hydrodynamic properties which range from a Porous Fractured Matrix (PFM) to thin interconnected Conduit Systems (CS) whose diameters can range from fractions of a centimeter to tens of meters. This variability induces, for the discharge and recharge phenomena, temporal responses ranging from a few minutes to several months. In addition, except for the largest caves, it is generally not possible to enter the heart of the karst system to proceed at direct measurements of temperatures, 
compositions or flow rates. It is often unavoidable to treat the entire system as a "black box" whose physical properties are more or less well-known except at the entrance and exit. So, for several decades, studies of hydrology properties of karstic systems use time series of temperature recording and flows, often supplemented by borehole measurements and test pumping although the latter cannot take into account the local complexity of karst systems and that the results may be biased, for example, by the location of the borehole in the PFM or in the CS network. In the first case, the measures will be typical of a damped environment and mainly sensitive to long term changes while, in the second case, they will be more sensitive to abrupt and rapid events such as heavy rains or run-off.

These preliminary considerations justify the interest to study the karst systems as "black boxes". In this framework, they can be considered as Open Thermodynamic Systems that exchange water and heat energy with the atmosphere, rocks or other surface or underground water circulations. However, it is not always possible to obtain accurate assessments of flow mixing and energy exchanges that occur because the temperature cannot be considered without caution as a conservative tracer. Heat exchanges exist in the CS water, in the PFM and, through the walls, with the porous rocks. Despite these difficulties, recent studies have used the temperatures and surface and underground flows to assess the hydrological dynamics. Constantz (1998 and 2008) solved iteratively the heat equation by adjusting hydraulic conductivity and temperature. Tabbagh et al. (1999) estimated the magnitude of aquifer recharge by setting vertical values of measured temperature as boundary conditions to energy equations. Benderitter et al. (1993) used long series of several year temperature records years to assess reservoirs depths on the basis of temperature equilibrium between groundwater and rocks. The couplings between the temperature of underground streams, rainfall and flow rates were also used on an annual basis by Genthon et al. (2008) to characterize the slow drainage of the limestone lagoons. The same author also used the annual changes in temperature sources to determine the preferred path of deep rain water in karst cavities (Genthon et al., 2005). Finally, Karanjac and Altug (1980) used the temperature records, combined with the recession curves to estimate the hydraulic properties, recharge properties and hydraulic transmissivity of karst systems.
In general, external temperatures are subject to more or less rapid fluctuations depending on the sunlight, the daily cycle, the weather trend or season. Conversely, in depth, with the notable exception of phenomena consecutive to run-off or sudden rainstorms, the thermal fluctuations are damped in the CS and the PFM. Thus, most of the studies mentioned above made the assumption of rapid temperature fluctuation damping (Sinokrot and Stefan, 1993; Luetscher and Jeannin, 2004; Dogwiller and Wicks, 2005).

Our work aims to evaluate the influence of conservative temperature approximation based on the theoretical framework provided by the OTS. For this purpose, our theoretical development takes into account the different heat transfer possible between the different elements of the OTS. However, it is impossible for a "black box" like approach, to account for all of the natural karstic system complexity. While early models sometimes regarded karst as continuous media, more recent studies have shown the way for the inclusion of more complex internal structures (e.g., Covington et al., 2009; Luhmann et al., 2011; Covington et al., 2011; 2012). Following these works we have considered a cylindrical water saturated $\mathrm{CS}$, carried by an abscissa axis $\mathrm{x}$, separated from a cylindrical PFM by a permeable wall. This framework allows checking the mass and energy conservations solving water and rock temperatures in the different parts of the OTS with two different configurations : 1), a conservative tracer behavior for temperature in which the mixing between CS and PFM flows occurs in the CS without heat dissipation or dispersion in the CS, in the PFM or through the wall separating the CS from PFM (in the following this configuration is called AW for Adiabatic Wall); 2), the same dynamic of mixing between CS and PFM flows but with conductive heat dissipation within the CS in the PFM and through the wall that separates them (This configuration is called CW for Conductive Wall).

The overall morphological structure used for our study is that the conceptual model developed by White (2002 and 2003) for fluviokarst. This structure corresponds to the Cent-Fonts (Hérault, France) karstic system whose description is given in the Annex part and which serves as an illustrative example for a potential application of the method. In the White's fluviokarst model (redrawn in Figure 1a) the stream that dug the valley is partially lost in a sinkholes area at the entry of the CS. However, 
when it is not completely dried, the remaining of its surface course joins up with the river that drains the base level of the fluviokarstic system. Along the underground path, the CS receives a diffuse infiltration from the far field through the PFM. The outlet of the system is a resurgence which also joins up with the river draining the base level of the karstic system.

\section{Theoretical Approach}

The CS of karstic systems is often impossible to explore and it is often unavoidable to consider the CS and the PFM as a "black box" whose thermodynamic properties will be treated as an OTS.

Considering water as an incompressible fluid with constant physical parameters (heat capacity, thermal expansion, density, or viscosity, etc.), the equations of mass and energy have been written for AW and CW configurations. Under these conditions, the mass conservation equation

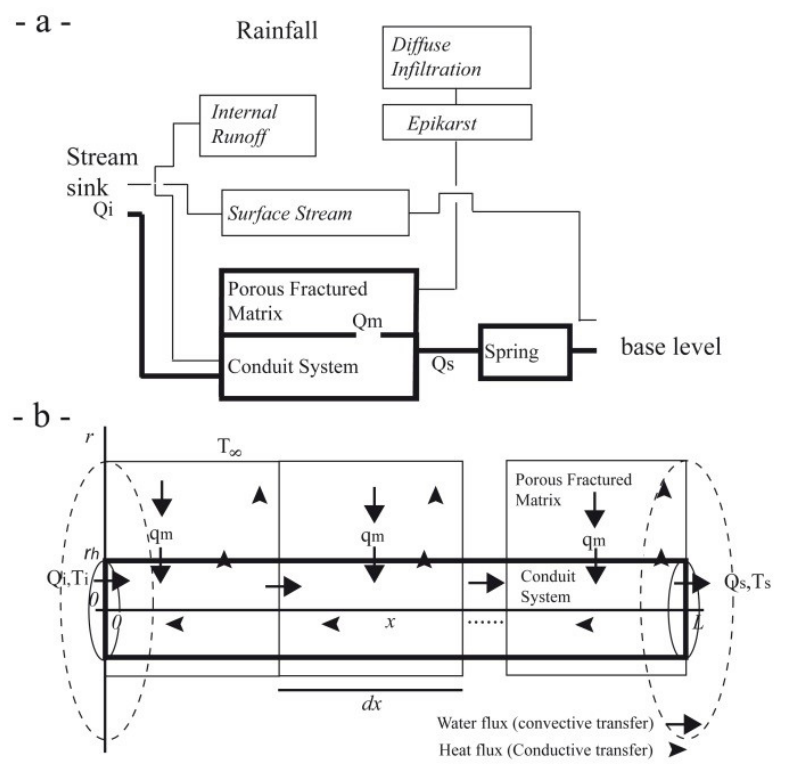

Figure 1. Fluviokarst model. (a) Conceptual fluviokarst structure proposed by White (2002 and 2003). The karstic aquifer is composed of a sinkholes area, of a saturated porous fractured matrix (PFM) drained by a conduit system (CS) and of a spring resurging at the base level. The White's model is restricted to recession periods with no surface stream and no run-off flow; (b) A sequence of open thermodynamic system sections is used to describe the fluvio-karstic system. Each section represents a slice of CS and PFM over which mass and energy balances will be checked. indicates that the water motion forms a zero divergence velocity field in the PFM and in the CS. In this study, we will also consider that the axial velocity, $v_{x}$, is zero in the PFM and that the radial velocity, $v_{r}$, is zero in the CS. Therefore, the mass conservation equation can be written in cylindrical coordinates $(x, r)$ as :

$$
\operatorname{div}(\vec{v})=\frac{\partial u_{x}}{\partial x}+\frac{\partial u_{r}}{\partial r}+\frac{u_{r}}{r}=0
$$

By linearity, it is possible to apply the Ostrogradski's or Green's theorem over each CS and PFM cylindrical section (of thickness $d x$ ) to convert the volume integral in a flux integral. The resulting Eq. 2 and Eq. 3 ensue for the PFM $\left(r \geq r_{h}\right)$ and for the CS $\left(r<r_{h}\right)$.

$$
\begin{aligned}
& r \geq r_{h}, x \in[0, L], u_{x}(x, r)=0, u_{r}(x, r)=\frac{r_{h} u_{r h}}{r} \\
& r<r_{h}, x \in[0, L], u_{r}(x, r)=0, \frac{\partial u_{x}(x, r)}{\partial x}=\frac{-2 u_{r h}}{r_{h}}
\end{aligned}
$$

Furthermore, to describe the CW configuration, it is necessary to take into account the conservation of thermal energy during the conductive transfers in the CS, in the PFM and between water and the rocks of the aquifer. Following the work developed by Covington et al (2011), we apply a conduction-temperature advection equation in PFM, but adding a new dispersion-conduction term that takes into account the cooling effects of the diffuse infiltration. In the PFM for $\left(r \geq r_{h}, x \in[0, \mathrm{~L}]\right)$, the energy conservation becomes Eq. 4:

$$
v_{r} \frac{\partial T}{\partial r}=D_{M}\left[\frac{\partial^{2} T}{\partial x^{2}}+\frac{\partial^{2} T}{\partial r^{2}}+\frac{2 \partial T}{r \partial r}\right]
$$

and, in the CS, for $\left(r<r_{h}, x \in[0, L]\right)$ :

$$
\begin{aligned}
v_{x} \frac{\partial T}{\partial x}=D_{W}\left[\frac{\partial^{2} T}{\partial x^{2}}\right. & \left.+\frac{2 \partial T}{r_{h} \partial r}\left(x, r_{h}\right)\right] \\
& -\frac{2 v_{r}\left(x, r_{h}\right)}{r_{h}}\left[T\left(x, r_{h}\right)-T(x, 0)\right]
\end{aligned}
$$

where $v_{x}, v_{r}$, and $T$ are the velocity and temperature fields depending on the cylindrical coordinates $x$ and $r$. However, to simplify the presentation of Eq. 5, these dependencies are not explicitly written except if the values are taken at specific points as $r=0$ or $r_{h}$.

In nature, karst systems exhibit great variability which is mainly due to the diversity of soils, to the extent of the watershed and the degree of karstification. CS present lengths ranging from tens of meters to a few tens of kilometers, while the permeability of the PFM, 
or the hydraulic radius of CS cover several orders of magnitude. Only a non-dimensional approach, classical for fluid mechanics studies, can describe such broad ranges of local properties through dimensionless number approach. The morphological aspect ratio of the karstic system, $r_{h} / L$, may display broader variations. However, hydrological and thermal properties of the various flows ( $T_{i}, Q_{i}$ for the intrusion at the sinkholes), but also the far field temperature and the rate of diffuse infiltration in the CS $(T \infty$ and $q M)$ also impact directly the temperature of the mixed water in the CS. Similarly, the physical parameters of rocks and water will also be gathered in these dimensionless groups as the viscosity or the ratio of water to rock thermal diffusivities.

Eqs. 1 to 5 have been rewritten using $L$, the CS length, as length scale; the discharge difference between the resurgence and the intrusive flow at the sinkholes area (divided by $\pi r_{h}^{2}$, the CS wall surface) defines a natural velocity scale for diffuse infiltration $V=\left(Q_{s}-Q_{i}\right) / \pi r_{h}{ }^{2}$. A time scale $\tau=L / V$ ensues from these two scales and, with these conditions, the relationships between dimensionless parameters of length, speed and time are respectively $x^{\prime}=x / L, u^{\prime}=u / V=u \pi r_{h}{ }^{2} /\left(Q_{s}-Q_{i}\right)$ and $t^{\prime}=t / \tau=t V / L$. The relationship that links the temperature to the dimensionless temperature is $T^{\prime}=(T-T i) /(T i-T$ $\infty)$. Within this framework, with $=r_{h} / L$ and $=u_{r h} / V$, the mass conservation equations in PFM and in CS become:

$$
\begin{aligned}
& r \geq \overline{r_{h}}, x \in[0,1], u_{x}^{\prime}\left(x^{\prime}, r^{\prime}\right)=0, u_{r}^{\prime}\left(x^{\prime}, r^{\prime}\right)=\frac{\overline{r_{h} u_{r h}}}{r^{\prime}}, \\
& r<\overline{r_{h}}, x \in[0,1], u_{r}^{\prime}\left(x^{\prime}, r^{\prime}\right)=0, \frac{\partial u_{x}^{\prime}(x t, r t)}{\partial x^{\prime}}=\frac{-2 \overline{u_{r h}}}{\overline{r_{h}}}
\end{aligned}
$$

and the energy equations in PFM and in CS become:

$$
\begin{aligned}
P e v_{r}^{\prime} & \frac{\partial T^{\prime}}{\partial r^{\prime}}=\bar{D}\left[\frac{\partial^{2} T^{\prime}}{\partial x^{\prime 2}}+\frac{\partial^{2} T^{\prime}}{\partial r^{\prime 2}}+\frac{2 \partial T^{\prime}}{r^{\prime} \partial r^{\prime}}\right] \\
P e v_{x}^{\prime} \frac{\partial T^{\prime}}{\partial x^{\prime}} & =\frac{\partial^{2} T^{\prime}}{\partial x^{\prime 2}}+\frac{4 P e}{\operatorname{Red} \operatorname{Pr}} \frac{\partial T^{\prime}}{\partial r^{\prime}}\left(x^{\prime}, \overline{r_{h}}\right) \\
& -\frac{4 P e^{2}}{\operatorname{RedPr}} v_{r}^{\prime}\left(x^{\prime}, \overline{r_{h}}\right)\left[T^{\prime}\left(x^{\prime}, 0\right)-T^{\prime}\left(x^{\prime}, \overline{r_{h}}\right)\right]
\end{aligned}
$$

Four groups of dimensionless numbers appear in Eqs. 6 to 9 . They are combinations between the Peclet number, $P e=L V / D_{w}$, the dimensionless thermal diffusivity, $D=$ $D_{m} / D_{w}$, the Prandtl number, $\operatorname{Pr}=v / D_{w}$, and the tubular Reynolds number $\mathrm{Red}=2 \mathrm{Vr}_{h} / v$.

The Prandtl number and the dimensionless thermal diffusivity depend only on the physical properties of water and rocks. In the following of this work, we will consider that the uncertainties on these parameters are significantly lower than those that might come from the variability of the hydrological. The latters mainly affect the Reynolds number (through the hydraulic radius of the CS) and the Peclet number (through the CS length). We therefore have built our parametric study on these two parameters which endorse most of the variability.

If the mass conservation equations (Eqs. 6 and 7) are not changed when the temperature is considered as a conservative tracer (AW case), this is not the case for the energy conservation equations (Eq. 8 and Eq. 9). In that case, it is necessary to consider the limit when the conductive heat dissipation disappears, that is to say when $D_{w}$ and $D_{m}->0$. In the PFM, for $\left(r \geq r_{h}, x \in[0, L]\right)$, it comes:

$$
\lim _{D_{w}, D_{M} \rightarrow 0} E q .8 \Leftrightarrow \frac{L V}{D_{w}} v^{\prime} r \frac{\partial T^{\prime}}{\partial r^{\prime}}=\frac{D_{m}}{D_{w}}\left[\frac{\partial^{2} T^{\prime}}{\partial x^{\prime 2}}+\frac{\partial^{2} T^{\prime}}{\partial r^{\prime 2}}+\frac{2 \partial T^{\prime}}{r^{\prime} \partial r t}\right]
$$

According to the constant thermal boundary condition for the far field temperature $\left(T{ }^{\prime} \infty=-1\right)$, the solution is given by Eq (11):

$$
\frac{\partial T^{\prime}}{\partial r^{\prime}}=0 \Leftrightarrow T^{\prime}=-1
$$

It follows as an expectable result that, in the absence of heat conduction, the PFM temperature is uniform and equal to those of the far field. Now, let's study the temperature equation in the CS for the AW case. It is then necessary to study the limit of Eq. 9 with zero thermal conductivity in water and rocks. In this case, if $D_{w}->0$, $P e->\infty$. Factoring and simplifying the term Pe on both sides of Eq. 9 leads to:

$$
\begin{aligned}
& \lim _{P e \rightarrow \infty} E q .9 \\
& \Leftrightarrow v_{x}^{\prime} \frac{\partial T^{\prime}}{\partial x^{\prime}}=0\left[\frac{\partial^{2} T^{\prime}}{\partial x^{\prime 2}}\right]+0\left[\frac{\partial T^{\prime}}{\partial r^{\prime}}\right]-\frac{2}{\bar{T}_{h}} v_{r}^{\prime}\left[T^{\prime} x^{\prime}, 0-T^{\prime}{ }_{X^{\prime}, \overline{r_{h}}}\right]
\end{aligned}
$$

That is to say:

$$
v_{x}^{\prime} \frac{\partial T^{\prime}}{\partial x^{\prime}}=-\frac{2}{\bar{r}_{h}} v_{r}^{\prime}\left[T^{\prime}{ }_{x^{\prime}, 0}-T^{\prime}{ }_{x^{\prime}, \overline{r_{h}}}\right],
$$

Eq. 13 matches the classical expression of the thermal energy conservation for a mixing without heat dissipation.

\section{Numerical Modeling}

Two numerical programs were written to solve the conservation of energy in the CS and in the PFM for both AW and CW configurations. They are based on finitedifference second order accurate methods (Douglas and 
Rachford, 1956). Both codes strictly comply with the same boundary conditions given by the flows entering the sinkholes, the rate of diffuse flow from PFM to $\mathrm{CS}$ and the intrusive and far field temperatures. The dimensionless temperature at the CS input is $\mathrm{T}_{\mathrm{i}}{ }_{\mathrm{i}}=0$, while the CS temperature at the CS resurgence remains free. The thermal boundary condition at the outer edges of the calculation grid $(r=0.02)$ is the far field dimensionless temperature, $T^{\prime} \infty=-1$.

For AW cases, a numerical 1-D code, solves Eq. 13 in the CS to calculates the temperature as a function of the abscissa $x$. On an other hand, for the CW configurations, Alternate Direction Implicit (ADI) finite-difference methods are used to successively solve the temperature equations in the radial and axial directions. The equations were discretized on a grid of 100 points in the radial direction and 500 points in the longitudinal direction. A convergence test stops the iterative process when a steady state solution is achieved (in effect when the relative changes of the temperature are less than $10^{-8}$ for all the points of the computation grid). Continuity and coupling of the temperature between the CS and the PFM are ensured by sharing the thermal boundary conditions along the CS wall: the temperature calculated in the CS serves as radial boundary condition for solving the temperature in the PFM. This method allows coupling the resolution in both parts of the solution while taking into account the heat dispersion in the CS and heat spreads within the CS and between CS and PFM.

A first comparison of the $\mathrm{AW}$ and $\mathrm{CW}$ hypotheses was conducted by introducing the values of the morphological, hydrological, and thermal main data observed on the Cent-Fonts fluviokarst site in summer 2005 (see annex part, and Ladouche et al., 2005 for report). Thus, a CS length $(\mathrm{L}=5,000 \mathrm{~m})$ is the distance, as the crow flies, between the sinkholes area of the Buèges stream and the Cent-Fonts resurgence near Hérault River (Figure 5); the hydraulic radius chosen for the CS $\left(r_{h}=5 \mathrm{~m}\right)$ corresponds to the speleological situation in the cave near the resurgence (Figure 6); the flow rate at the sinkhole is $Q_{i}=0.055 \mathrm{~m}^{3} / \mathrm{s}$; the output stream at the resurgence is $Q_{s}=0.392 \mathrm{~m}^{3} / \mathrm{s}$; temperature at sinkhole is $T i=295.25^{\circ} \mathrm{K}\left(22.1^{\circ} \mathrm{C}\right)$; and far-field temperature is $T \infty=285.35{ }^{\circ} \mathrm{K}\left(12.2^{\circ} \mathrm{C}\right.$ ) (Ladouche et al., 2005). Further, we assumed a water thermal diffusivity $D_{w}=1.4310^{-7} \mathrm{~m}^{2} / \mathrm{s}$, and for PFM $D_{m}=4.03$ $10^{-6} \mathrm{~m}^{2} / \mathrm{s}$ (Pechnig et al., 2007). These values lead to the following dimensionless numbers: $P e=1.5010^{8}$, Red $=4.2910^{4}, \mathrm{Pr}=6.99$ and $\mathrm{Dm} / \mathrm{Dw}=9.93$.

Figure 2 shows the temperature field obtained for the $\mathrm{CW}$ configuration in PFM and CS, after resolutions of Eqs. 8 and 9. The monotonic cooling with abscissa along the CS results from the mixing of the cold diffuse flow with the hot water that enters the CS at the sinkholes area. However, in the PFM around the CS, close to the sinkholes area, the heat transmitted by conduction in the PFM, induces thermal boundary layers that encounters the cooling flow from the far field. At a radial distance of a few tens of meters away from the CS wall, the thermal boundary layers attenuate rapidly and fall to a temperature close those of the far field.

On the other hand, solving Eq.13 provides the temperature of CS water with the conservative tracer hypothesis (AW). In Figure 3, the Comparison of the blue curve (AW configuration) with the red curve (CW configuration) shows that the CS cooling is overestimated by the conservative temperature hypothesis. Due to the

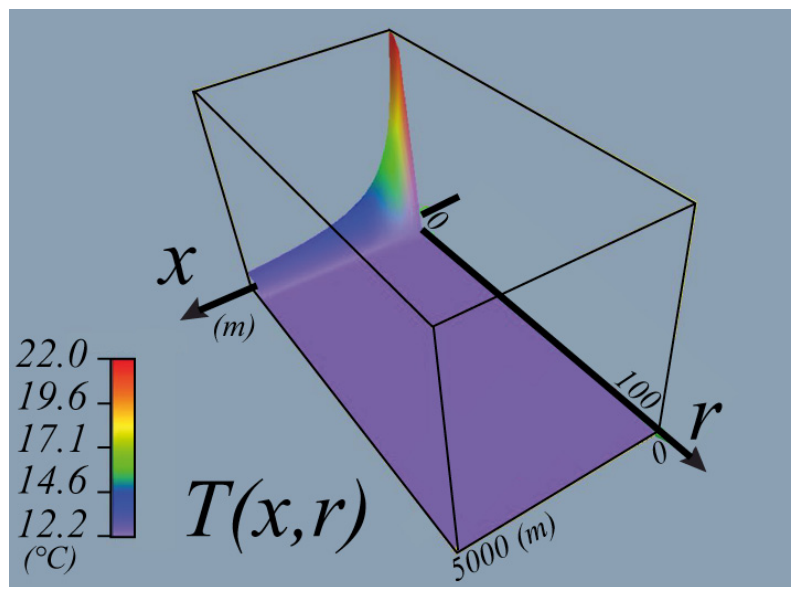

Figure 2. CS and PFM temperature field. Illustrative example of the temperature field obtained in the CS and in the PFM with CW model. The morphological, hydrological, and physical parameters are characteristic of the Cent-Fonts (Hérault, France) fluviokarst system $\left(L=5,000 \mathrm{~m}, r_{h}=5 \mathrm{~m}, D_{m}=1.4210^{-}\right.$ ${ }^{\circ} \mathrm{m}^{2} / \mathrm{s}, D_{w}=1.4310^{-7} \mathrm{~m}^{2} / \mathrm{s}, T_{i}=295.25^{\circ} \mathrm{K}(22.1$ $\left.{ }^{\circ} \mathrm{C}\right), T_{\infty} \stackrel{w}{=} 285.35^{\circ} \mathrm{K}\left(12.2^{\circ} \mathrm{C}\right), Q_{i}=0.055 \mathrm{~m}^{3} / \mathrm{s}$, $\left.Q_{s}=0.392 \mathrm{~m}^{3} / \mathrm{s}\right)$. These values lead to $P e=$ $\left.1.5010^{8}, \operatorname{Red}=4.2910^{4}, \operatorname{Pr}=6.99\right)$ and $D_{m} / D_{w}=$ 9.93. The computation has been done in the dimensionless space. The temperature field has been rescaled in the physical space for drawing. 
effect of heat conduction in the CS, in the PFM and from the CS to PFM, a significant amount of thermal energy is consumed in the PFM to hold the hot conductive boundary layers against the diffuse cold water advection from the far field. Both curves diverge quickly where the maximum of energy is required to maintain the higher boundary layers (abscissa close to the sinkholes area). For larger abscissa, the decrease of the boundary layer amplitude induces a stabilization of the temperature difference between the two AW and CW assumptions.

The final temperature difference at the CS output corresponds to the thermal energy used to maintain the equilibrium of water and rocks temperature in the PFM in spite of antagonistic effects between conductive and advective heat flows while the thermal diffusivity of the rock is about one order of magnitude higher than those of water. This final temperature difference bears a firstorder information on the error due to the conservative tracer assumption in the PFM. Beyond this simple illustrative example, the next section will describe the results of a parametric study realized to reach a more general quantification of this error.

\section{Parametric Study}

The high variability of morphological, hydrological and thermal properties of karst systems stresses the need to conduct a parametric study to cover the wide ranges of dimensionless parameters that describe them. In this context, we conducted a systematic study of the temperature relative deviation (Eq. 14) obtained in the CS for both CW and AW configurations. It's dimensionless expression is given by Eq. 15 .

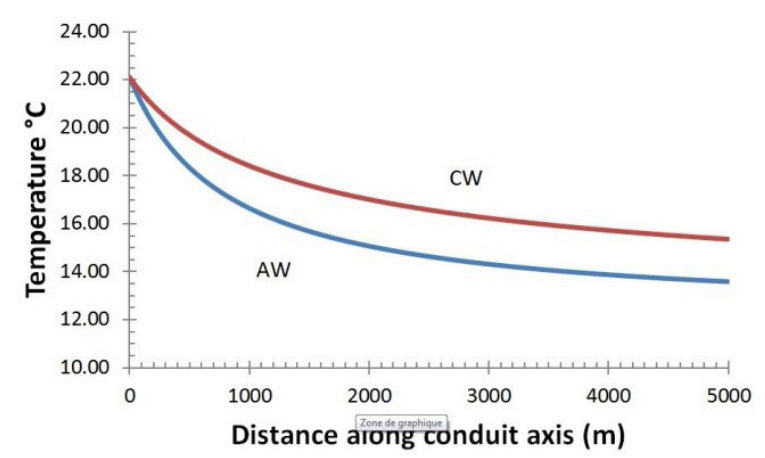

Figure 3. AW versus CW, CS temperature. Comparison of CS temperature obtained with the CW model (red curve) and the AW model (blue curve).

$$
\begin{aligned}
\varepsilon(x) & =\frac{T_{C W}(x, 0)-T_{A W}(x)}{T_{C W}(x, 0)} \\
\varepsilon^{\prime}(x) & =\frac{T^{\prime} C W\left(x^{\prime}, 0\right)-T^{\prime} A W\left(x^{\prime}\right)}{T_{\prime} C W\left(x^{\prime}, 0\right)+\frac{T_{\infty}}{\left(T_{i}-T_{\infty}\right)}}
\end{aligned}
$$

As mentioned above we have restrained our attention in this section, to the study of the effects of Reynolds numbers and Peclet numbers changes. The Peclet number $\left(P e=L V / D_{w}\right)$ measures the ratio of advection to conduction characteristic times. Therefore, the higher $P e$, the preeminent effect of conduction compared to advection. Moreover, it directly characterizes the CS length, which is one of the most variable morphological properties of karst systems. The second entry of this study is the Reynolds number ( $\left.\operatorname{Red}=2 V r_{h} / v\right)$, which is characteristic of a second highly variable morphological parameter of the karstic system : the CS hydraulic radius. These two quantities are mathematically linked through the Prandtl number $P e=(L$ Red $P r) / r_{h}$. However, it should be noted that in the energy equation (Eq. 9), $P e$ is present at the numerator of the Eq. 9's terms while Red is present at the denominator. According to their increasing or decreasing values, they will induce opposite effects on these terms that characterize the relative importance of conduction, dispersion and advection.

To better understand the cross-influence of these two parameters we have, initially studied the behavior of the $\varepsilon^{\prime}(x)$ depending on $P e$ (ranging from $10^{6}$ to $10^{9}$ ) at constant $\operatorname{Red}\left(\mathrm{Red}=4.2910^{4}\right.$, the value previously obtained for the Cent-Fonts fluviokarst); then, in a second step, we studied the behavior of $\varepsilon^{\prime}(x)$ by varying Red from $10^{3}$ to $10^{7}$ at constant $P e\left(P e=1.50010^{8}\right)$. The results of these two steps are shown respectively on the upper and lower parts of Figure 4. The left panels show the evolution $\varepsilon^{\prime}(x)$ as a function of the abscissa $\mathrm{x}$ in the $\mathrm{CS}$, while the right panels give an overview of the final errors at the system output.

In any case, at the sinkholes area location $(x=0)$, the error is zero. This result is expected since at this particular stage, no energy transfer by conduction has occurred between hot intrusive water at sinkhole and cold intrusive water from PFM diffuse infiltration. Conversely, as soon as the offset $x$ of the sinkhole increases, $\varepsilon^{\prime}(x)$ increases especially as the boundary layers observed in Figure 2 are stronger. For higher abscissa $x$, the rate of variation of $\varepsilon^{\prime}(x)$ decreases. In fact, two distinct types of behavior are displayed for $\varepsilon^{\prime}(x)$ on the left panels of Figure 4.

The firsts are characterized by curves that start from 
zero (for $\mathrm{x}=0$ ), reach maxima, then decrease more or less slowly for higher abscissa. The seconds shows monotonic growths of $\varepsilon^{\prime}(x)$. The transitions between the two regimes are progressive and occur with the increases of the test parameters ( $P e$ or Red). However, it should be noted that, in all the cases, the error curves $\varepsilon$ ' $(x)$ remain well below $1 \%$.

Let's now examine in more detail how $\varepsilon^{\prime}(x)$ evolves with $P e$ (at constant Red) (Figure 4, top panels). According to the physical meaning of the Peclet number, its decreasing corresponds to a decrease of the relative importance of conductive transfers face to the advective ones, homogeneously in the whole system. In fact, for the lowest values of $P e\left(10^{6}\right.$ and $510^{6}$; Figure 4, top left panel, light brown and red curves) $\varepsilon$ ' ( $(x)$ increases monotonically with $x$. However it converges uniformly to zero for further decreases of $P e$. Conversely, for the highest values of $P e\left(510^{8}\right.$ and $10^{9}$, Figure 4, top left panel, dark blue and purple curves) $\varepsilon$ ' ( $(x)$ reaches maxima for abscissa close to the sinkhole area (low values of $x$ ). In these cases, the amplitudes of these maxima decrease with increasing Pe. $\varepsilon$ ' ( $(x)$ finally also tends to zero for all the value of the abscissa. In any cases, the maximum of the relative errors are achieved for intermediate values of the dimensionless parameter $P e$. They remain less than 0.01 (actually 0.0092 for $P e=710^{7}$ ). For the highest values of $P e$, we recognize the effects of the limit $D_{w}->0$ described in Section 2 since in that case the assimilation of temperature to a conservative tracer is equivalent to consider the $P e_{->}>\infty$ limit that induces that $\varepsilon '(x)$, which measures the difference between the two $\mathrm{AW}$ and $\mathrm{CW}$ hypotheses, tends to zero.

Let's now consider the physical situation that prevails when Red increases at constant $P e$. This scenario allows to assess the influence of the CS hydraulic radius $\left(\right.$ Red $\left.=2 V_{h} / v\right)$. Since $R e d$ and $P e$ perform in antagonistic manners $n$ Eq. 9, it is now for the highest values of Red, $\left(10^{6}\right.$ and $10^{7}$, Figure 4 , bottom left panel, orange and red curves) that $\varepsilon$ ' (x) displays uniform convergence to zero. Conversely, this I for the lowest values of Red $\left(10^{3}\right.$ and $10^{4}$, Figure 4, bottom, left panel curves purple and dark blue) that $\varepsilon^{\prime}(x)$ reaches maxima, for low values of the abscissa, in the sinkholes area.

The right panels of Figure 4 show synoptic representations of the relative errors $\varepsilon$ ' $(x)$ at the output of the CS (following the variation of $\mathrm{Pe}$ (top panel) and of Red (bottom panel)). The maxima of error are encountered for intermediate values of both parameters. They remain less than $1 \%$ (the maximum values of 0.0092 and 0.0062 are respectively achieved for $P e=710^{7}$ and $R e d=10^{5}$ ). It is also interesting to emphasize that the results obtained for the illustrative example of Cent-Fonts fluviokarstic system naturally fall within this bounded error range.

\section{Summary and Discussion}

The purpose of this work is to try to assess a first order of the error done by considering temperature as a conservative tracer in fluvio-karstic systems. For that, we developed and solved the energy and mass conservation equations, leaned against the White's conceptual model for fluviokarst, and within the theoretical background of OTS. We applied theses equations to a cylindrical CS, which receives hot intrusive water from a sinkholes area and, through a PFM, a cold diffuse flow from the far field all along its underground path. This set forms an OTS in which we studied two configurations. The first (AW) assumes that no conductive heat is lost in the CS water, neither between the PFM water and the aquifer embedding rocks; nor between CS and PFM through the permeable separation wall. The second $(\mathrm{CW})$ takes into account the conductive heat dissipation in CS water, in PFM and the dispersion of heat by conduction through the PFM wall. These equations have been rescaled that leads to a new system of equations where four groups of dimensionless numbers measure the relative magnitudes of the various conductive and advective terms. Solving these equations in both configurations with strictly similar thermal and dynamic, boundary conditions allows assessing a first order of the errors induced by the conservative tracer assumption for temperature.

However, it is clear that our results lead only to a firstorder information about this error because the method cannot completely eliminate or estimate other sources of error. Indeed, in order to proceed to the numerical solving of the mass and energy equations we need to consider laminar flows, in a saturated CS. Furthermore, we must keep in mind that the method is better applied during the recession periods when the hydraulic regime of the fluviokarst is as close as possible of a steady state. Further studies are needed, to go beyond the first results presented in this paper. However, some of our results seem encouraging since whereas the variability of karst systems has largely been accounted by the range extent of the parametric exploration, errors in the 


\section{Evolution of error versus Pe (at constant Red)}

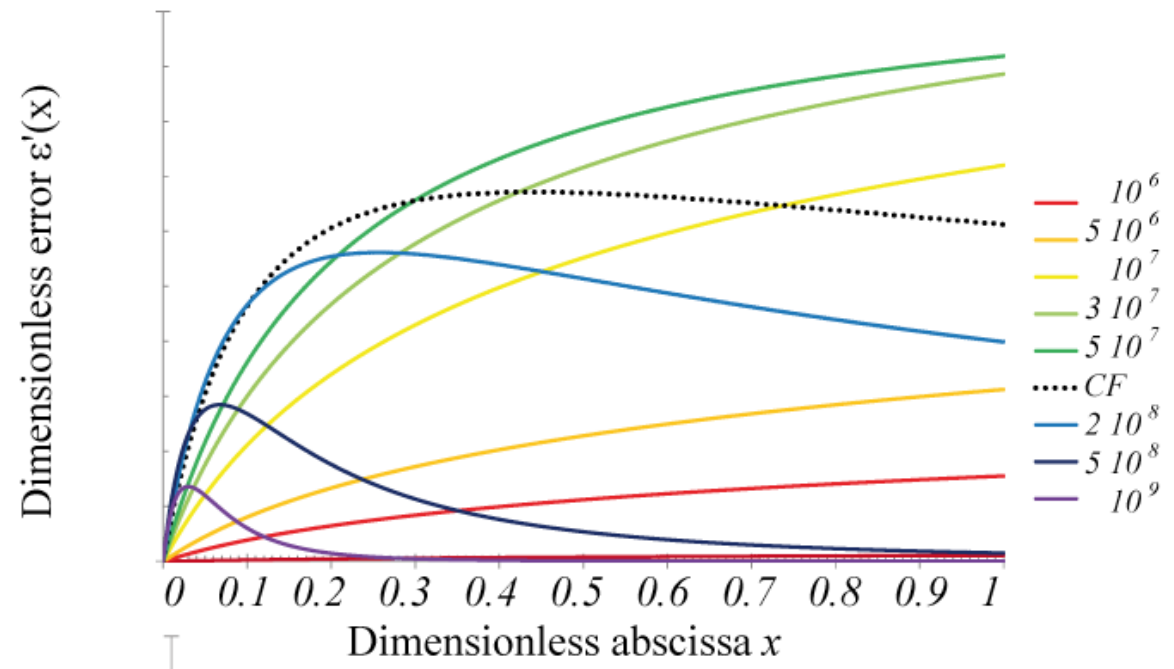

Evolution of error versus Red (at constant Pe)

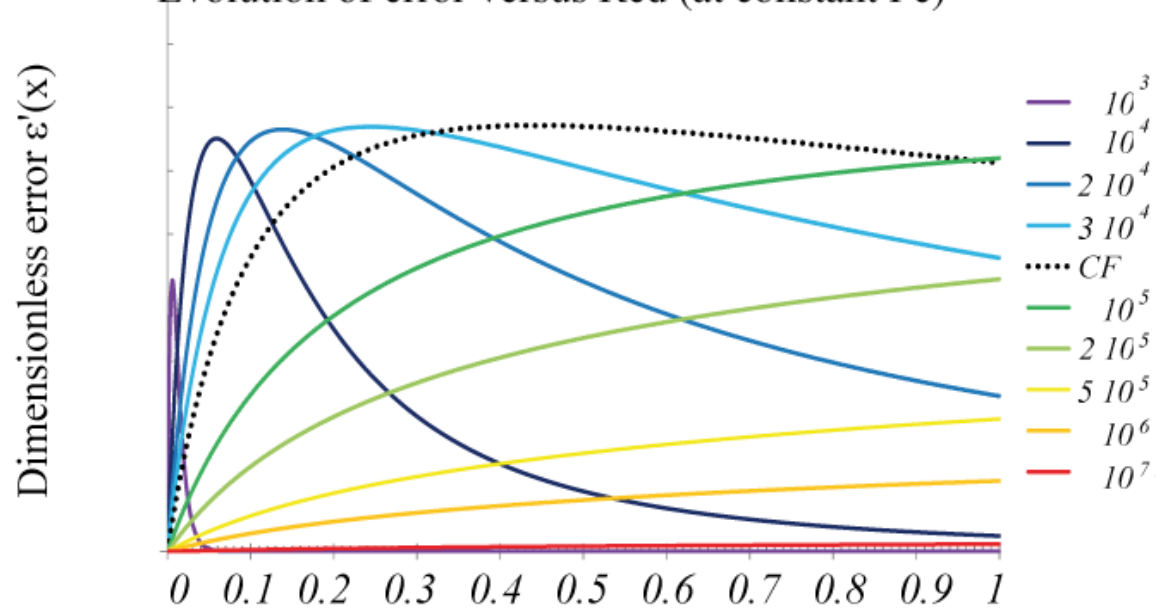

Dimensionless abscissa $x$
Error at output

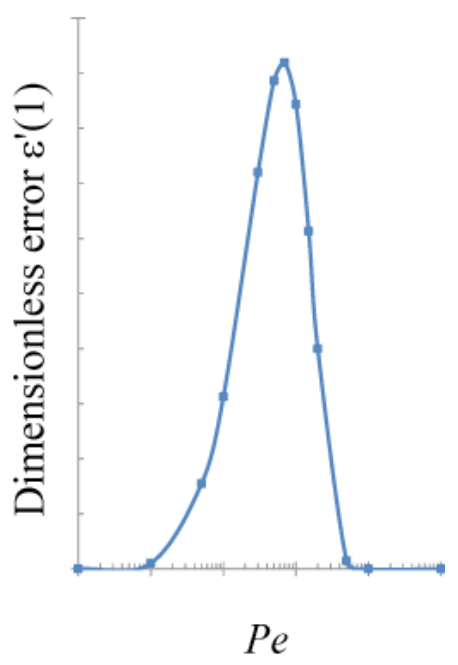

Error at output

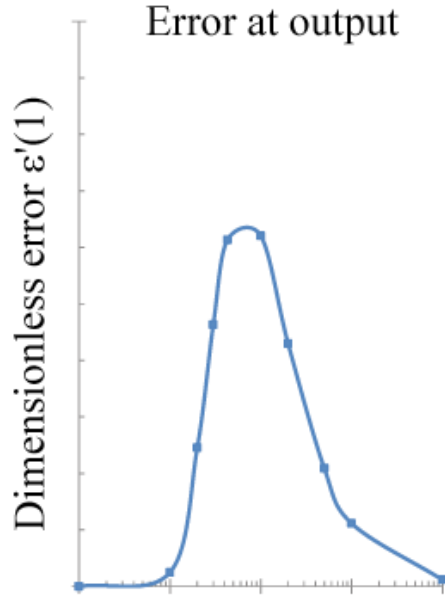

Red

Figure 4. Parametric study of the error $e^{\prime}(\mathrm{x})$ versus $P e$ and Red numbers. Evolution of the dimensionless error $\varepsilon^{\prime}(x)$ (Eq. 15) versus Pe(at constant Red, top panels) and versus Red (at constant $\mathrm{Pe}$, lower panels). Left panels show the evolution of $\varepsilon^{\prime}(x)$ in the CS while the right panels give a synthetic view of the errors reached at the output of the CS $(x=1)$ versus the dimensionless parameters.

dimensionless space are limited to less than $1 \%$ (actually 0.0092 to 0.007$)$. The error volume formed by the error curves, due to the variations of these two parameters, converges to zero for their extremal values. Meanwhile, the maximum of errors are reached for median parameter values that are characteristic of realistic karstic system in both morphology and hydrological considerations.

From the results obtained in the non-dimensional space, it is possible to evaluate an upper bound of the first order of the error induced by the conservative temperature assumption for particular karstic system by reversing the scaling scheme. This quite simple calculation allows quick retrieving of the error in the physical space thank to the morphological and hydrological properties of a particular fluviokarstic system. The comparison of model results with field data open the possibility of critical analyses and may offer a decision-making support for its applicability to local cases. If we focus our attention on the illustrative example given by the Cent-Fonts fluviokarstic system, Figure 4 shows that the relative error $\varepsilon$ ' $(x)$ 
reaches, 0.00613 at the exit of the resurgence in the dimensionless field $\left(\mathrm{Pe}=1.5010^{8}\right.$ and Red $4.29=$ $\left.10^{4}\right)$. When rescaled in the physical domain, the error $\varepsilon(x)$ indicates a temperature disparity $\mathrm{T}_{\mathrm{CW}}-\mathrm{T}_{\mathrm{AW}}$ $=1.77{ }^{\circ} \mathrm{C}(0.00613 \times 288.50)$. It is clear that this information can be used to infer potential propagation of uncertainties in calculations or cooling rates. It can also be used to propose a calibration of the effects of the conservative temperature approximation depending on the equations and on the dimensionless properties of the karstic system (Machetel and Yuen, in preparation). In these next works, we will focus on examining that the theoretical evaluation of the error proposed in this work is compatible with the thermal data available on other karst systems. Indeed, at the sight of this study, it seems possible to use the results from a theoretical analysis to coerce information on internal thermal conditions of the karstic system. The results seem open interesting research opportunities that may be applicable to other systems whose workings are often described in terms of "black box", as geothermal or hydrothermal studies.

\section{Appendix : Cent-Fonts resurgence (Hérault, France)}

The Cent-Fonts resurgence is the base level outlet of a fluviokarstic system, which watershed covers an area of 40-60 km² (Figure 5). This basin is located north of Montpellier, on the right bank of the Hérault River within a thick dolomitic Middle and Late Jurassic limestone sequence.

Several structural, geological, geochemical and hydrological studies were devoted to this karstic system for several decades (Paloc, 1967; Camus, 1997; Petelet et al., 1998; Schoen et al., 1999; Ladouche et al., 2002; Petelet-Giraud, 2003; Aquilina et al., 2005; Ladouche et al., 2005; Aquilina et al., 2006, Marechal et al., 2008; Dörfliger et al., 2009). The watershed is bounded to the north and northeast by the Cevennes fault, the surface course of the intermittent Buèges stream, and southeast by the Hérault River, which drains its base level. The watershed encompasses the upper course of the Bueges stream, which flows on an impermeable Triassic outcrop until it reaches a sinkholes area crossing a batonian dolomitic area a few kilometers downstream from SaintJean-de-Buèges (Figure 5). From that point, the Buèges stream surface course forms a valley mostly dried up that joins the Hérault River a few kilometers upstream of the confluence with the Lamalou. On the other hand, the underground pathway from Buèges sinkhole to the Cent Fonts resurgence was established by tracing (Dubois, 1962; Schoen et al., 1999).

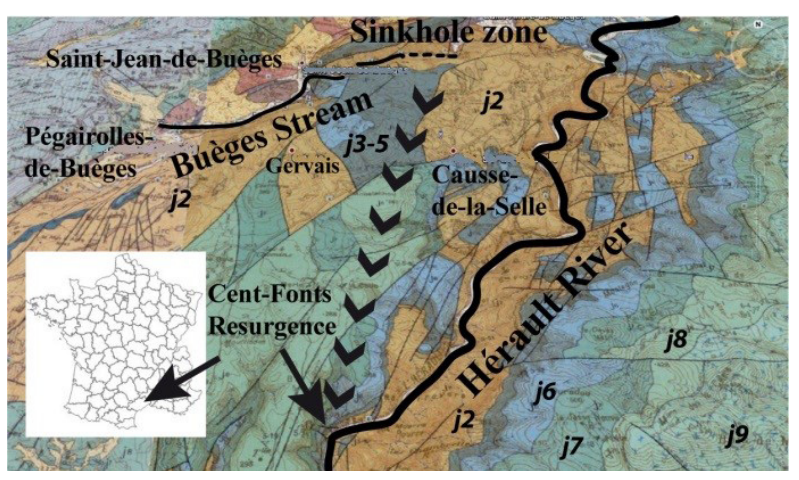

Figure 5. Cent-Fonts fluviokarst watershed. Redrawn on the Hérault geological map 1/50000 France BRGM (J2: Bajocian; J35: Bathonian, Callovian, Oxfordian; J6: Kimmeridgian; J7: Tithonian). The Cent-Fonts fluviokarst watershed covers about $60 \mathrm{~km}^{2}$ including $10 \mathrm{~km}^{2}$ for the Buèges resurgence watershed (Schoen et al, 1999).

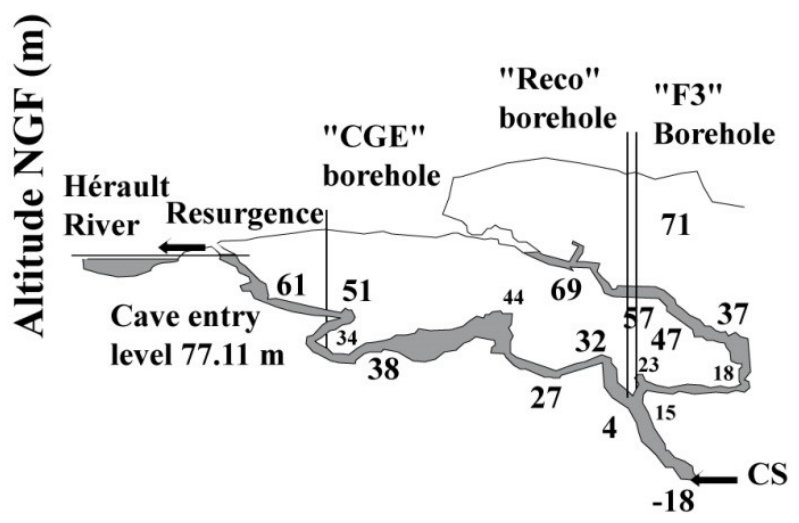

Figure 6. CS map of the Cent-Fonts resurgence. Unrolled 3-D speleological map of the Cent-Fonts CS near the resurgence. Vertical distances $(m)$ are conserved. Depths below the main cave entry are given in $m$ (italic). During the summer 2005 pumping tests, piezometric heads and temperatures have been measured in the so-called "CGE ॥, " Reco " and "F3 " boreholes. Temperature and discharges were also recorded at the output of the pumping device located in the "F3" borehole, at the entry of the Buèges Stream swallow zone and in the Hérault River near the resurgence (Ladouche et al., 2005). 


\section{Table}

\begin{tabular}{|c|c|c|c|}
\hline \multicolumn{4}{|c|}{ Acronyms } \\
\hline AW & \multicolumn{3}{|c|}{ Adiabatic Wall } \\
\hline $\mathrm{CS}$ & \multicolumn{3}{|c|}{ Conduit System } \\
\hline $\mathrm{CW}$ & \multicolumn{3}{|c|}{ Conductive Wall } \\
\hline $\mathrm{CV}$ & \multicolumn{3}{|c|}{ Control volume } \\
\hline OTS & \multicolumn{3}{|c|}{ Open Thermodynamic System } \\
\hline PFM & \multicolumn{3}{|c|}{ Porous Fractured Matrix } \\
\hline Not. & Units & $\mathrm{CF}$ & Description \\
\hline$D_{m}$ & $\left(\mathrm{~m}^{2} / \mathrm{s}\right)$ & $1.4210^{-6}$ & $\begin{array}{l}\text { Matrix thermal } \\
\text { diffusivity }\end{array}$ \\
\hline$D_{w}$ & $\left(\mathrm{~m}^{2} / \mathrm{s}\right)$ & $1.4310^{-7}$ & $\begin{array}{l}\text { Water thermal } \\
\text { diffusivity }\end{array}$ \\
\hline$v$ & $\left(\mathrm{~m}^{2} / \mathrm{s}\right)$ & $10^{-6}$ & $\begin{array}{l}\text { Kinematic } \\
\text { viscosity }\end{array}$ \\
\hline$L$ & $(\mathrm{~m})$ & $510^{3}$ & CS Lengh \\
\hline$q_{m}$ & $(\mathrm{~m} / \mathrm{s})$ & - & $\begin{array}{l}\text { surfacic } \\
\text { discharge of } \\
\text { PFM }\end{array}$ \\
\hline$Q_{i}$ & $\left(\mathrm{~m}^{3} / \mathrm{s}\right)$ & 0.055 & $\begin{array}{l}\text { discharge of } \\
\text { stream sink }\end{array}$ \\
\hline$Q_{s}$ & $\left(\mathrm{~m}^{3} / \mathrm{s}\right)$ & 0.392 & $\begin{array}{l}\text { discharge of } \\
\text { spring }\end{array}$ \\
\hline$r$ & (m) & - & $\begin{array}{l}\text { radial } \\
\text { coordinate }\end{array}$ \\
\hline$r_{h}$ & (m) & 5 & $\begin{array}{l}\text { half hydraulic } \\
\text { radius }\end{array}$ \\
\hline$t$ & (s) & - & time \\
\hline$T(x, r)$ & $\left({ }^{\circ} \mathrm{K}\right)$ & - & temperature \\
\hline$T \infty$ & $\begin{array}{l}\left({ }^{\circ} \mathrm{K}\right) \\
285.35\end{array}$ & $\begin{array}{l}\text { far field } \\
\text { temperature }\end{array}$ & \\
\hline $\mathrm{T}_{\mathrm{i}}$ & $\left({ }^{\circ} \mathrm{K}\right)$ & 295.25 & $\begin{array}{l}\text { Temperature of } \\
\text { stream sink }\end{array}$ \\
\hline $\mathrm{v}$ & $(\mathrm{m} / \mathrm{s})$ & - & $\begin{array}{l}\text { Fluid velocity } \\
\text { vector }\end{array}$ \\
\hline$v_{r}(x, r)$ & $(\mathrm{m} / \mathrm{s})$ & - & $\begin{array}{l}\text { Velocity r } \\
\text { component }\end{array}$ \\
\hline$v_{x}(x, r)$ & $(\mathrm{m} / \mathrm{s})$ & - & $\begin{array}{l}\text { Velocity } \mathrm{x} \\
\text { component }\end{array}$ \\
\hline$V$ & $(\mathrm{~m} / \mathrm{s})$ & $4.2910^{-3}$ & Velocity scale \\
\hline$x$ & (m) & - & $\begin{array}{l}\text { abscisse } \\
\text { coordinate }\end{array}$ \\
\hline \multicolumn{4}{|c|}{ Dimensionless numbers } \\
\hline$D$ & $D_{m} / D_{w}$ & 9.93 & $\begin{array}{l}\text { Thermal } \\
\text { diffusivity ratio }\end{array}$ \\
\hline$P e$ & \multicolumn{2}{|c|}{$L V / D_{w} 1.5010^{8}$} & $\begin{array}{l}\text { Conduit Peclet } \\
\text { number }\end{array}$ \\
\hline $\operatorname{Pr}$ & $v / D_{w}$ & 6.99 & Prandtl number \\
\hline Red & \multicolumn{2}{|c|}{$\left(2 V r_{h}\right) / v 4.2910^{4}$} & $\begin{array}{l}\text { Conduit } \\
\text { Reynolds } \\
\text { number }\end{array}$ \\
\hline
\end{tabular}

The Cent-Fonts karstic system takes root in a dolomite layer Bathonian of 150 to $300 \mathrm{~m}$ thick and probably extends into the layer of Aalénien - Bajocian underlying. It forms a fluviokarst by catching the Buèges Stream loss at the Sint-Jeande-Buèges sinkhole and by draining the watershed rainfalls which percolate through an upper Jurassic epikarstic layer (Petelet-Giraud et al., 2000). Therefore, the Cent-Fonts karstic system is similar to the conceptual model of White (Figure 1a) with a CS collecting sinkholes losses and a diffuse infiltration flowing from a PFM into the CS. After $5 \mathrm{~km}$ of underground path (as the crow flies), the CS poors through the Cent-Fonts resurgence in the Herault River which drains the base level of the karstic system. The resurgence discharges through a shallow network of springs that flow a few tens of centimeters above the Hérault (Schoen et al, 1999). During the dry season, the resurgence discharge ranges from 0.250 to $0.340 \mathrm{~m}^{3} / \mathrm{s}$ summer (Maréchal et al., 2008). The detailed structure of the CS near the resurgence output (Figure 6) has been explored by divers (Vasseur, 1993). In the maped area, the CS cross section ranges between 4 to $16 \mathrm{~m}^{2}$ (Dörfliger et al., 2009). The Cent-Fonts resurgence has undergone numerous field observations since 1997. Several years of flow measurements have been recorded to calibrate the base flow of the Cent-Fonts resurgence, of the Buèges stream and the losses in the sinkhole area. A pumping test campaign was conducted during the summer of 2005 by BRGM under contracting authority of Conseil Général de l'Hérault. This campaign provides to scientists many temperature and flow records from surface and deep holes measurements (Ladouche et al., 2005).

\section{Acknowledgments}

The authors thank the Conseil General de l'Hérault for the electronic transmission of the whole set of data of the 2005, Cent-Fonts pumping test campaign. We also thank Alexander Calvin, Martin Saar, and Andrew Luhmann for friendly and useful discussions about heat transfer in karstic systems. Research received funds from geochemistry program from the National Science Foundation. This work received a financial support from the Organising Committee of the International Workshop of Deep Geothermal Systems, Wuhan, China, June 29-30, 2012. 


\section{References}

Aquilina L, Ladouche B, Dörfliger N. 2005. Recharge processes in karstic systems investigated through the correlation of chemical and isotopic composition of rain and spring-waters, Applied Geochemistry. 20 (12): 2189-2206.

Aquilina L, Ladouche B, Dörfliger N. 2006. Water storage and transfer in the epikarst of karstic systems during high flow periods. Journal of Hydrology. 327 (3-4): 472-485.

Benderitter Y, Roy B, Tabbagh A. 1993. Flow characterization through heat transfer evidence in a carbonate fractured medium: first approach. Water Res Res. 29: 3741-3747.

Camus H. 1997. Formation des réseaux karstiques et creusements des vallées: l'exemple du Larzac méridionnal, Hérault, France. Karstologia. 29: 23-42.

Constantz J. 1998. Interaction between stream temperature, stream flow, and groundwater exchanges in Alpine streams. Water Resources Research. 34 (7): 1609-1615.

Constantz J. 2008. Heat as a tracer to determine streambed water exchanges. Water Resources Research. 44: W00D10. http://dx.doi. org/10.1029/2008WR006996.

Covington MD, Wicks CM, Saar MO. 2009. A dimensionless number describing the effects of recharge and geometry on discharge from simple karstic aquifers. Water Res Res. 45: W11410. http://dx.doi.org/10.1029/2009WR008004.

Covington MD, Luhmann AJ, Gabrovsek F, Saar MO, Wicks CM. 2011. Mechanisms of heat exchange between water and rock in karst conduit. Water Resources Research. 47: W10514. http://dx.doi. org/10.1029/2011WR010683.

Covington MD, Luhmann AJ, Wicks CM, Saar MO. 2012. Process length scales and longitudinal damping in kart conduits, Mechanisms of heat exchange between water and rock in karst conduit. J Geophys Res. 117: P01025. http://dx.doi. org/10.1029/2011/JF002212.

Dogwiller T, Wicks C. 2005. Thermal variations in the hyporheic zone of a karst stream. Speleogenesis and Evolution of Karst Aquifers. 3 (1): 1-11.

Dörfliger N, Fleury P, Ladouche B. 2009. Inverse modeling approach to allogenic karst system characterization. Ground Water. 47 (3): 414-426. http://dx.doi.org/10.1111/j.17456584.2008.00517.x.

Douglas J, Rachford HH. 1956. On the numerical solution of heat conduction problems in two and three space variables. Trans Am Math Soc. 82: 966-968.
Dubois P. 1962. Etude des réseaux souterrains des rivières Buèges et Virenque (Bas Languedoc), paper presented au 2e congrès international de spéléologie, Salerne, 2-12 Octobre 1958.

Genthon P, Wirrmann D, Hoibian T, Allenbach M. 2008. Steady water level and temperature in a karstic system: the case of the coral Lifou Island (SW Pacific). C R Geoscience. 340: 513-522.

Genthon P, Bataille A, Fromant A, D'Hulst D, Bourges F. 2005. Temperature as a marker for karstic waters hydrodynamics. Inferences from 1 year recording at La Peyrere cave (Ariege, France). Journal of Hydrology. 311 (1-4): 157-171.

Jemcov I. 2007. Water supply potential and optimal exploitation capacity of karst aquifer systems. Environmental Geology. 51: 767-773.

Karanjac J, Altug A. 1980, Karstic spring recession hydrograph and water temperature analysis Oymapinar Dam Project, Turkey. Journal of Hydrology. 45 (3-4): 203-217.

Ladouche B, Dörfliger N, Pouget R, Petit V, Thiery D, Golaz C. 2002. Caractérisation du fonctionnement des systèmes karstiques nord-montpelliérains, rapport du programme 1999-2001-Buèges, RP 51584-FR., BRGM, 2002.

Ladouche B, Maréchal J C, Dörfliger N, Lachassagne P, Lanini S, Le Strat P. 2005. Pompage d'essai sur le système karstique des Cent-Fonts (Commune de Causse de la Selle, Hérault), Présentation et interprétation des données recueillies, BRGM RP54426-FR, 82 ill., 45 tabl., 9 ann., 245 pp.

Luetscher M, Jeannin PY. 2004. Temperature distribution in karst systems: the role of air and water fluxes. Terra Nova. 16: 344-350.

Luhmann AJ, Covington MD, Peters AJ, Alexander SC, Anger CT, Green JA, Runkel AC, Alexander EC. 2011. Classification of thermal patterns at karst spring and cave streams. Ground Water. 49 (3): 324-335.

Marechal JC, Ladouche B, Dörfliger N. 2008. Interpretation of pumping tests in a mixed flow karst system. Wat Res Res. 44: W05401. http:// dx.doi.org/10.1029/2007WR006288.

Paloc H. 1967. Carte hydrogéologique de la France, région karstique nord-montpelliéraine, notice explicative. Mémoire BRGM. n50.

Pechnig R, Mottaghy D, Koch A, Jorand R, Clauser C. 2007. Prediction of thermal properties for Mesozoic rocks of southern Germany, European Geothermal Conference, GeothermischeVereinigunge.V. - Bundesverband Geothermi. 
Petelet E, Luck JM, Ben Ohtman D, Negrel P, Aquilina L. 1998. Geochemistry and water dynamics of a medium-sized watershed: the Herault, southern France 1. Organization of the different water reservoirs as constrained by $\mathrm{Sr}$ isotopes, major, and trace elements. Chemical Geology. 150 (1-2): 63-83.

Petelet-Giraud E, Dörfliger N, Crochet P. 2000.

RISK : méthode d'évaluation multicritère de la vulnérabilité des aquifères karstiques. Application aux systèmes des Fontanilles et cent-font (Hérault, sud de la France). Hydrogéologie. 4: pp.71-88.

Petelet-Giraud E. 2003. Dynamic scheme of water circulation in karstic aquifers as constrained by $\mathrm{Sr}$ and $\mathrm{Pb}$ isotopes. Application to the Herault watershed, Southern France. Hydrogeology Journal. 11 (5): 560-573.

Schoen R, Bakalowicz M, Ladouche B, Aquilina L. 1999. Caractérisation du fonctionnement des systèmes karstiques nord-montpelliérains. Rapport BRGM R 40939, volume III, 91 p.

Sinokrot BA, Stefan HG. 1993, Stream temperature dynamics measurements and modeling. Wat Res Res. 29: 2299-2312.

Tabbagh A, Bendjoudi H, Benderitter Y. 1999. Determination of recharge in unsaturated soils using temperature monitoring. Water Resources Research. 35 (8): 2439-2446.

Vasseur F. 1993. Les explorations de l'Association Celadon. Info-plongée. 63: 17-21.

Weber KA, Perry RG. 2006. Groundwater abstraction impacts on spring flow and base flow in the Hillsborough River Basin, Florida, USA. Hydrogeology Journal. 14 (7): 1252-1264.

White WB. 2002. Karst hydrology: recent developments and open questions. Engineering Geology. 65 (2-3): 85-105.

White WB. 2003. Conceptual models for karstic aquifers. Speleogenesis and evolution of karst aquifers. 1 (1): 6. 